\title{
REVIEW
}

\section{Oligodendrocyte Fate after Spinal Cord Injury}

\author{
Akshata Almad, ${ }^{1,2}$ F. Rezan Sahinkaya,,2 and Dana M. McTigue ${ }^{2,3}$ \\ ${ }^{1}$ Neuroscience Graduate Studies Program, ${ }^{2}$ Center for Brain and Spinal Cord Repair, ${ }^{3}$ Department of Neuroscience, Ohio State \\ University, 788 Biomedical Research Tower, 460 W. 12th Ave., Columbus, Ohio 43210
}

\begin{abstract}
Summary: Oligodendrocytes (OLs) are particularly susceptible to the toxicity of the acute lesion environment after spinal cord injury (SCI). They undergo both necrosis and apoptosis acutely, with apoptosis continuing at chronic time points. Loss of OLs causes demyelination and impairs axon function and survival. In parallel, a rapid and protracted OL progenitor cell proliferative response occurs, especially at the lesion borders. Proliferating and migrating OL progenitor cells differentiate into myelinating OLs, which remyelinate demyelinated axons starting at 2 weeks postinjury. The progression of OL lineage cells into mature OLs in the adult after injury recapitulates development to some degree, owing to the plethora of factors within the injury milieu. Although robust, this endogenous oligogenic response is insufficient against OL loss and demyelination. First, in this review we analyze the major
\end{abstract}

spatial-temporal mechanisms of OL loss, replacement, and myelination, with the purpose of highlighting potential areas of intervention after SCI. We then discuss studies on OL protection and replacement. Growth factors have been used both to boost the endogenous progenitor response, and in conjunction with progenitor transplantation to facilitate survival and OL fate. Considerable progress has been made with embryonic stem cellderived cells and adult neural progenitor cells. For therapies targeting oligogenesis to be successful, endogenous responses and the effects of the acute and chronic lesion environment on OL lineage cells must be understood in detail, and in relation, the optimal therapeutic window for such strategies must also be determined. Key Words: Myelin, polydendrocytes, excitotoxicity, inflammation, transplant, macrophage.

\section{INTRODUCTION}

Trauma to the spinal cord results in massive tissue destruction and cellular damage at and around the injury site. The initial physical assault to the spinal cord causes vascular rupture, hemorrhage and necrosis of neurons and glia at the injury site. This is followed by "secondary injury cascades," including blood-brain barrier breakdown, reduced blood flow and ischemia, excitotoxicity, free radical production, and immune cell infiltration [1]. These events result in continued loss of neurons and glia. This review will focus on mechanisms involved in loss of oligodendrocytes (OLs) after spinal cord injury (SCI), spontaneous replacement of endogenous OLs, and therapies targeted at protecting or replacing OLs.
Electronic supplementary material The online version of this article (doi:10.1007/s13311-011-0033-5) contains supplementary material, which is available to authorized users.

Address correspondence and reprint requests to: Dana M. McTigue Ph.D., Department of Neuroscience, Ohio State University, 788 Biomedical Research Tower, 460 W. 12th Ave., Columbus, OH 43210. E-mail: dana.mctigue@osumc.edu.

\section{SPINAL CORD INJURY AND OLIGODENDROCYTE LOSS}

Rodent models of SCI have been used extensively to gain insight into the cellular pathology occurring after injury. Research in the 1990s revealed that OLs are quite susceptible to damage after SCI, and are lost to acute necrosis and acute/ subacute apoptosis [2-6]. In a rat spinal contusion model, acute OL loss was detected within 15 minutes postinjury with continual loss occurring for $4 \mathrm{~h}[2,5]$. Similarly, in a mouse SCI model, OL numbers decreased within $24 \mathrm{~h}$ and steadily declined by 3 to 7 days postinjury (dpi) [7]. Prolonged OL apoptosis has been detected for at least 3 weeks following rat spinal contusion; dying cells were especially prominent in degenerating axon tracts rostral and caudal to the injury site $[3,8]$. Apoptotic OLs have also been noted in tissue from nonhuman primates and human patients revealing that this phenomenon is common across multiple injury models and after human SCI $[3,9,10]$.

\section{Early mechanisms of OL loss}

Many factors in the acute lesion environment can be toxic to OLs. For instance, proteolytic enzymes released from necrotic cells or damaged vessels can digest cells and vascular structures, which potentiates damage and structural 
compromise. Blood components can induce apoptosis and necrosis of cultured oligodendrocyte progenitor cells (OPCs), and at low concentrations can inhibit OPC proliferation and migration [11]. Ischemia and reperfusion are also major contributors to free radical formation, including reactive oxygen and nitrogen species. The resulting oxidative stress damages cellular membranes, proteins, and DNA. OLs are particularly vulnerable to oxidative stress (and excitotoxicity, see as follows) due to their high metabolic activity, high levels of intracellular iron and low concentration of antioxidants, such as glutathione [12].

Another secondary injury cascade implicated in OL loss after SCI is excitotoxicity. Work by McAdoo et al. [13] showed that glutamate was elevated rapidly after SCI, and when comparable concentrations of glutamate were microinjected into intact spinal cords, OL death ensued [14]. OLs express multiple glutamate receptor subtypes, including (2amino-3-(5-methyl-3-oxo-1,2-oxazol-4-yl)propanoic acid) (AMPA), kainate receptors, and n-methyl-d-aspartic acid (NMDA) receptors [15]. Thus, they are vulnerable to elevated glutamate levels. AMPA receptor activation can also stimulate OL progenitor migration [16]. Given that glutamate levels are likely highest in regions of greatest pathology, this pro-migratory OPC response may either serve to call in cell replacements for dying OLs and/or cause further cell death by drawing them into a toxic milieu of dying cells and lethal molecules.

Excitotoxicity is not restricted to glutamate, but also occurs following adenosine-5'-triphosphate (ATP) binding to $\mathrm{P}_{2} \mathrm{X}_{7}$ receptors on OLs $[17,18]$. ATP is elevated within $2 \mathrm{~h}$ after SCI and is likely released by multiple cell types, including OLs $[17,19]$. Both glutamate and ATP lead to calcium overload, which can trigger multiple intracellular pathways leading to cell demise $[19,20]$. In addition, cytokines such as tumor necrosis factor- $\alpha$ and interleukin (IL)-1 $\beta$, which are up-regulated within minutes after SCI $[21,22]$, can exacerbate excitotoxicity by impairing glutamate uptake [23].

Infiltrating neutrophils and activated microglia release products that can promote OL loss, including free radicals, pro-inflammatory cytokines, glutamate, and proteases (reviewed by Donnelly and Popovich [22]). Lymphocytes reach peak levels in the rodent spinal cord at $\sim 1$ week postinjury [24], and can lyse OLs directly [25] and/or induce apoptosis by releasing molecules that activate death receptors via tumor necrosis factor$\alpha$, IL-2, and interferon gamma (IFN $\gamma$ ). OL death may also occur through the death receptors Fas and 775 nerve growth factor receptor (p75NGFR) via their respective ligands (FasL and NGF) [26-28]. In addition to apoptosis and necrosis, autophagy has recently been shown to occur for at least 21 days following spinal hemisection, with Beclin-1 expression (a promoter of autophagy) highest in OLs compared to neurons or astrocytes [29].

\section{Chronic OL loss after SCI}

OL apoptosis has been detected at 2 to 3 weeks after SCI and has been attributed to wallerian degeneration of axons. The hypothesis for wallerian loss of OLs is that axons provide trophic support for OLs; hence, the loss of axons results in subsequent loss of the associated OLs. In rodents, this diminution of OLs occurs several segments away from the epicenter, extending rostro-caudally along the degenerating axon tracts $[6,8]$. However, a recent study determined that axon degeneration alone (in the absence of trauma) was not sufficient to kill OLs and in fact evoked OPC proliferation and new OL formation [30]. The authors contrasted this response to OL apoptosis rostral to spinal contusion in which they noted that markers of oxidative stress were present in OLs following contusion injury but not dorsal rhizotomy. Therefore, the lack of OL loss with pure axon degeneration could be due to lack of oxidative stress, or possibly from continued support of OLs from unsevered axons.

\section{Microglia, macrophages, and OLs}

Microglia and macrophages derived from infiltrating monocytes have both destructive and reparative properties after SCI (reviewed by Jones et al. [31]). Numerous studies have attempted to describe interactions of microglia/macrophages and OPCs/OLs. In a chemical demyelination model, infiltrating macrophages promote OPC recruitment [32], perhaps through release of growth factors or glutamate, as previously mentioned. Recent in vitro data revealed that microglia and macrophages isolated from contused rodent spinal cords produce factors that inhibit the growth of OPC-containing cell spheres isolated from the same spinal cords [33]. Work by our group showed that activation of intraspinal microglia using different receptor ligands results in either OPC death or OPC proliferation and marked OL genesis [34]. A follow-up study revealed that OPC proliferation and $\mathrm{OL}$ genesis occurring in response to intraspinal microglia activation was significantly reduced by iron chelation, revealing that available iron is necessary for a maximal pro-oligogenic response of microglial activation [35]. This is in accordance with in vitro evidence showing that the iron status of microglia affects their functional relationship with OPCs [36]. In addition, recent work by our group revealed that OPCs internalize macrophage-derived ferritin both in vivo and in vitro, suggesting ferritin may serve as a pro-oligogenic signal between macrophages and OPCs (Schonberg and McTigue, personal observation). It is clear that microglia/macrophages have considerable potential for shaping OPC responses to injury, and more research is needed to characterize the diverse interplay between these two cell types. 


\section{DEMYELINATION AND REMYELINATION AFTER SCI}

Early work studying myelin damage after SCI noted prevalent vesicular degeneration of myelin and widening of peri-axonal spaces within hours after injury [37, 38]. Furthermore, a significant loss of major myelin proteins following SCI has been detected in rodents and monkeys [38-41]. Some of the earliest studies examining demyelination after SCI in cats and rodents determined that demyelination was fairly prevalent during the first 2 weeks postinjury [40-42]. This was confirmed in more recent work using tissue from dogs that had sustained a spontaneous SCI [43]. In human tissue, demyelinated axons have been detected to a variable degree along lesion borders from 1 to 22 years postinjury [9]. Thus, demyelination, especially acutely, appears to be a consistent finding after SCI and may contribute to functional deficits by abrogating action potential conduction through denuded segments.

The lack of large-scale, chronic demyelination after SCI is due, at least in part, to spontaneous remyelination by OLs and Schwann cells. Axon remyelination in the adult central nervous system (CNS) was first documented by Drs. Richard and Mary Bunge [44, 45]. Subsequent work has consistently detected axon remyelination after SCI, typically beginning around 2 weeks postinjury [40, 41]. Intriguingly, when axons are remyelinated by OLs, the myelin is thinner and the internodes are shorter compared to normal myelin [46]. Despite these characteristics, remyelination can restore axonal conduction velocity, as elegantly illustrated by Smith et al. [47]. As a proof of principal, studies by the Duncan laboratory [48] bolstered the notion that remyelination restores function. They showed that remyelination by transplanted OLs in myelin-deficient animals restored conduction velocity to near normal. Similarly, Jeffery and Blakemore [49] found that with the onset of remyelination, functional deficits disappeared in an ethidium bromide demyelination model. Thus, spontaneous remyelination after SCI likely preserves function of spared intact axons.

The phenomenon of remyelination likely also maintains axon integrity. Indeed, bare axons are thought to be vulnerable to pathological environments, and thereby more susceptible to transection [50]. There is a symbiotic relationship between axons and OLs that exceeds simple electrical insulation. Indeed, recent data shows that the absence of functional peroxisomes in OLs results in widespread axon damage and demyelination [51], indicating that the relationship between axons and OLs is complex and that OLs play much more than a passive insulating role. Persistent demyelination after SCI will likely exacerbate axonal loss [52], making OLs indispensable not only for the proper functioning of axons but also for their survival.

\section{REPLACEMENT OF OLS BY ENDOGENOUS PROGENITORS AFTER SCI}

Although remyelination after SCI has been acknowledged for many years, identifying the cells responsible for remyelinating axons was not clear-cut. However, work by Blakemore and Keirstead [53] revealed that mature OLs, which are post-mitotic, do not contribute to remyelination; instead, remyelination is mediated by endogenous proliferating progenitor cells. These OL progenitors cells (commonly called OPCs or polydendrocytes) are present throughout the adult gray and white matter, and respond to demyelination by proliferating and migrating into the demyelinated zone [53-56]. Adult OPCs, typically identified by Nerve/glial antigen 2 (NG2) or Platelet derived growth factor receptor (PDGFR $\alpha$ ) expression, are thought to be a heterogeneous cell population, only some of which function as OPCs (for review, see Nishiyama et al. [57] and Trotter et al. [58]).

Work from our group revealed that NG2 cells proliferate for at least 4 weeks after SCI [59]. Several other groups have corroborated this robust proliferative response in rodents and primates [7, 60-65]. Interestingly, accumulation of mitotic NG2 cells is greatest along SCI lesion borders [66], which may be due to differential up-regulation of growth factors in this region [67]. Recent work by Sellers et al. [68] demonstrated differential cell fate of NG2 cells after SCI; NG2 cells generated $24 \mathrm{~h}$ after injury gave rise to astrocytes, whereas those generated 1 week postinjury produced OLs. However, more recent data using lineage tracing following SCI call the ability of OPCs to give rise to astrocytes after SCI into question [69]. Direct evidence that NG2 cells contribute to replacement of mature OLs after SCI was recently provided using the CNP-EGFP $\left(2^{\prime}, 3^{\prime}-\right.$ Cyclic-nucleotide 3'-phosphodiesterase gene-enhanced green fluorescent protein) mouse to definitively show that $\mathrm{EGFP}^{+} \mathrm{NG2}^{+}$cells differentiate into OLs after SCI [70]. Thus, at least a portion of NG2 cells function as OL progenitors after SCI.

\section{MAKING OF THE OLIGODENDROCYTES}

After SCI, there is recapitulation of developmental factors integral to OL specification, migration, and differentiation. Two major factors regulating OL specification during development are the Sonic hedgehog and protein bone morphogenetic factor (BMP) (for review, see Nicolay et al. [71]). Sonic hedgehog, which is pro-oligogenic, is upregulated acutely in neurons and OLs after injury, and remains high for several weeks [72]. A rise in BMP and its cognate receptor was observed for 2 weeks after injury [7274]. BMP can drive stem/progenitor cells toward an astrocyte rather than OL fate [75]. 
Also, post-SCI treatment with a BMP antagonist favored differentiation of OPCs into OLs, suggesting that endogenous OL genesis may be hampered by upregulated BMP $[68,76]$.

\section{Survival and proliferation of OPCs}

Developmentally, OPC survival and proliferation depend on many of the same growth factors and cytokines altered by CNS injury. For instance, plateletderived growth factor-A (PDGF-A) is a potent mitogen that is essential for proper OL development [77, 78]. Animals lacking PDGF-A have severely reduced OL numbers, and mice over-expressing PDGF-A form a surplus of OLs [79-81]. Expression of PDGF-A after SCI has not been the specific focus of studies to date, but at least one microarray study determined that PDGF-A is decreased after SCI [82]. PDGF-A can also synergize with fibroblast growth factor-2 (FGF-2) and maintain OPCs in a continual mitotic renewal state [83-86]. Although PDGF levels after SCI are not definitively known, FGF-2 (an OPC mitogen on its own) is upregulated for at least 28 days, corresponding to the time of active OPC proliferation [67, 87-90].

Another important factor in promoting OPC proliferation and OL survival is insulin-like growth factor (IGF) [91, 92]. IGF may play a role in oligogenesis after SCI as increased astrocytic production of IGF-1 was noted in a cryogenic SCI model [93]. Importantly, IGF can amplify the action of FGF-2 and PDGF on OPCs [94], suggesting it may increase the effectiveness of these factors if/when present after SCI. Ciliary neurotrophic factor (CNTF), a pleiotropic cytokine, is also important for OPC survival and proliferation $[95,96]$. CNTF and its receptor are upregulated early after SCI, and our laboratory detected a robust increase chronically in CNTF and its downstream signaling molecules along SCI lesion borders, which corresponds regionally and temporally to elevated OPC proliferation and maturation $[67,89,97]$. CNTF can also increase FGF-2 and receptors for FGF and IGF, thereby increasing the sensitivity of OL lineage cells to these factors [98, 99]. The pronounced oligogenesis after injury in the astrocytic glial scar region, and the ability of astrocytes to secrete PDGF, FGF-2, IGF, and CNTF reveal astrocytes likely sit center stage in terms of influencing post-SCI OL production.

Neurotrophins are another important class of molecules that have multiple effects on spinal cord parenchyma in general and OLs in particular. Neurotrophin (NT-3) promotes OPC survival and proliferation by activating the Mitogen-activated protein kinases (MAPK) signaling cascade $[96,100,101]$. After SCI, increased levels of NT-3 and brain-derived neurotrophic factor (BDNF) have been detected in rats and primates [102104]. Interestingly, transplantation of fibroblasts overexpressing NT-3 or BDNF significantly increased the number of new OLs and myelinated axons after SCI, suggesting that these signaling pathways can be enhanced [105].

Chemokines, best known as chemotactic molecules for inflammatory cells, also affect OL lineage cells. The chemokine CXCL1 influences OPC proliferation and migration developmentally [119] and is up-regulated acutely after SCI [106]. CXCL12 (also known as SDF$1 \alpha$ ) was very recently shown to promote OPC differentiation and remyelination; furthermore, the same study showed that $\mathrm{NG} 2+$ progenitors express CXCR4, the relevant receptor [107]. Previous work by Dziembowska et al. [108], published in 2005, showed that the chemokine receptor CXCR4 is important in OPC survival and migration [109]. Expression of CXCL12 and its receptor CXCR4 are increased after SCI, suggesting that CXCL12 may contribute to postinjury oligogenesis [110]. Although a number of other chemokines are present after SCI, their role in OL genesis has not been investigated.

\section{To be or not to be: OPCs to OLs}

The lineage progression from precursor cell to a myelinating OL requires the timely exit from the cell cycle and transcriptional initiation of differentiation and myelin genes. A number of growth factors, cytokines, cell cycle proteins, and transcriptional factors play a role in this process and their expression after SCI coincides with endogenous oligogenesis.

IL-1 $\beta$, a chemokine secreted by astrocytes and microglia (and to some extent by OLs), is up-regulated within 45 minutes after SCI, peaks at $12 \mathrm{~h}$, and returns to basal levels by $48 \mathrm{~h}$ [21]. IL-1 $\beta$ promotes OPC and OL survival, and also induces OPC differentiation by counteracting the proliferative actions of PDGF [111]. Leukemia inhibitory factor (LIF) belongs to the IL-6 family of cytokines and in vitro studies suggest that LIF enhances OPC differentiation [112]. Receptor-mediated LIF transport across spinal cord blood vessels has been detected during the first week postinjury [113]; therefore, endogenous systemic LIF may contribute to OPC differentiation after SCI. Another well-described cytokine is transforming growth factor (TGF) $\beta 1$, which is significantly increased, along with its receptors, after SCI in rodents and humans [114-116]. TGF $\beta 1$ may have divergent effects on OPCs. Studies have shown it can inhibit OPC proliferation and promote differentiation into mature OLs [117, 118]. However, a recent study revealed that TGF $\beta 1$ stimulates Jagged1 expression by astrocytes, which inhibits OPC differentiation [119]. Thus, the role of TGF $\beta 1$ on OL genesis after SCI is likely complex.

Many transcription factors also regulate OPC differentiation, some of which belong to the nuclear receptor super family. One such factor, thyroid hormone receptor is recognized as a potent regulator of OPC differ- 
entiation, and decreased levels of thyroid hormone have been detected in SCI individuals [120]. Single or double knockouts of thyroid hormone receptor display normal OPC development but severe dysmyelination due to lack of OPC maturation [121]. Other nuclear receptors that regulate OPC differentiation are peroxisome proliferator activated receptor (PPAR) $-\delta$ and retinoic acid receptor [122-124]. Our laboratory has reported a temporal increase of PPAR- $\delta$ after SCI, first in NG2 cells, followed by expression in new OLs 1 to 4 weeks postinjury [125]. Thus, PPAR- $\delta$ displays the correct spatial-temporal distribution to contribute to postinjury OPC differentiation. Retinoic acid is thought to inhibit OL differentiation during development and thereby allow dispersal of OPCs throughout the tissue [124]. After SCI, a subpopulation of $\mathrm{NG} 2$ cells produce retinoic acid [126], which as previously stated may reduce differentiation of progenitors into mature OLs. Thus, many endogenous factors with the potential to regulate differentiation of progenitors are present after injury; manipulating these molecules may be an effective strategy to boost endogenous oligogenesis and improve myelination.

\section{Turning on myelination}

Axon-derived signals are known to regulate myelination. During development, OPCs express the notch receptor and axons express the notch ligand Jagged-1. As axons down-regulate Jagged-1, notch signaling is attenuated in OPCs, which allows them to differentiate into mature OLs that eventually myelinate the axon [127]. Reactivation of notch signaling has been reported after SCI, which could potentially hinder remyelination [128]. Another axon signal is polysialylated form of the neural cell adhesion molecule (PSA-NCAM), which can prevent OL myelination and is thought to contribute to demyelination in multiple sclerosis [129-131]. PSANCAM is increased after SCI and is expressed by reactive astrocytes [132], and thereby may prevent myelination of axons in or around the glial scar.

Leucine rich repeat and Ig domain containing 1 (LINGO-1) is an Nogo-66 Receptor (NgR) co-receptor expressed on the surface of OLs, and is an important negative regulator of myelination [133, 134]. Administration of a LINGO antagonist after SCI promoted both neuron and OL survival and improved functional recovery [135]. These results suggest that LINGO is present and functional after SCI, and may thereby reduce spontaneous remyelination.

\section{Epigenetic and post-translational regulation}

Histone deacetylases (HDACs) are proteins involved in chromatin remodeling by removal of acetyl groups from histones. HDAC activity, especially that of HDACs 1,2 , and 11 , is necessary for OPC differentiation into mature OLs by promoting myelin gene expression and repressing inhibitors of OPC differentiation [136, 137]. Pharmacological blockage of HDAC activity in demyelinating lesions resulted in inefficient remyelination, revealing that baseline HDAC activity is needed for myelin repair in the adult CNS [138]. To date, HDAC expression after SCI has not been investigated, except in a preliminary report [139]. Thus, we recently examined if HDAC messenger RNA (mRNA) levels are altered by spinal contusion in rats. We observed that HDAC1 levels were unaltered but HDAC2 mRNA dropped precipitously by day 3 after SCI (FIG. 1a, b). HDAC3 showed a progressive decline, which was significant at 7 to $14 \mathrm{dpi}$ (FIG. 1c). HDAC-11 displayed a complex post-SCI pattern, in that it decreased at $3 \mathrm{dpi}$, but rose significantly at $14 \mathrm{dpi}$. The early loss of HDACs 2 and 11 postinjury may lead to increased transcription of OL differentiation inhibitors.

A relatively nascent field is post-transcriptional regulation of proteins in OLs by micro RNAs (miRNAs). miRNAs are small noncoding RNAs that typically block translation of target mRNAs. In the previous 2 years, studies have shown that the expression of many miRNAs is dynamically altered as OPCs differentiate into mature OLs $[140,141]$. Three studies used OL-specific promoters to knockout Dicer, a protein necessary for miRNA production, which essentially eliminates miRNAs from OL and OPCs [141-143]. The results revealed either a developmental disruption in gliogenesis [143] or that progenitor cells were formed but were unable to differentiate [141, 142]. Furthermore, the studies revealed that miRNAs decrease expression of proteins needed to maintain cells in a proliferative state. For instance, miR-219 prevents translation of $\operatorname{PDFGR} \alpha$, Sox6, FoxJ3, Hes5, and ZFP238, all of which play a role in OPC proliferation or inhibition of differentiation $[141,142]$. Importantly, what we believe to be the first article to examine miRNA expression after SCI demonstrated that expression of $\sim 100$ miRNAs are significantly altered by SCI [144]. Interestingly, several miRNA expressed by OLs during the differentiation process are significantly down-regulated during the first week postinjury [10,141, 142, 144, 145], which could hamper differentiation acutely after SCI. Because this is precisely the time of maximal OPC proliferation [59], lack of these miRNAs may decrease the ability to leverage the large population of newly generated progenitors to fully differentiate into myelinating OLs and replace those lost to injury.

Thus, a great variety of factors (not all of which are described here) involved in OL formation, survival, and myelination are present after SCI and likely positively or negatively influence oligogenesis in the injured cord (FIG. 2). To understand the mechanisms integral to endogenous myelination and to maximize repair by endogenous or transplanted cells, much more work is 

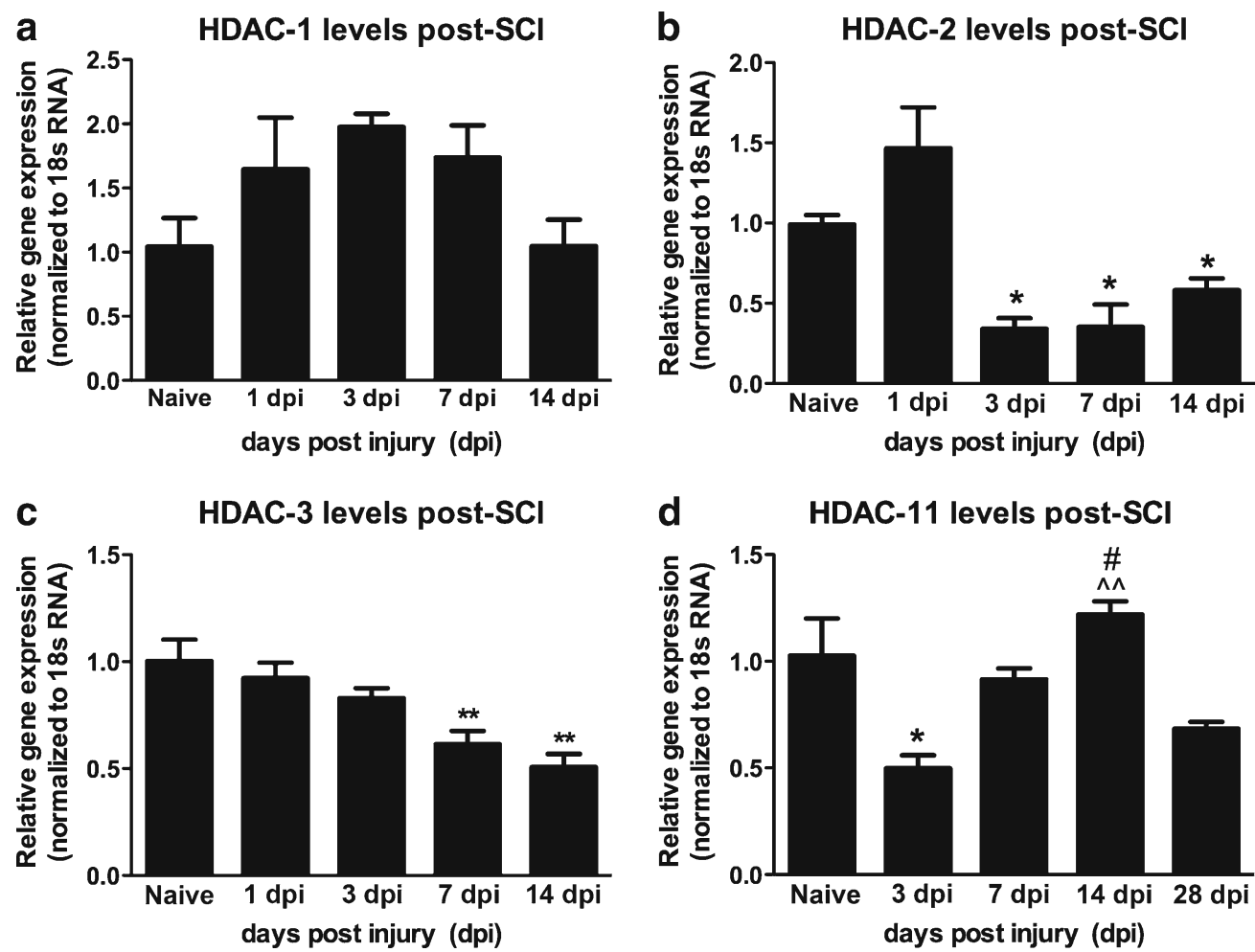

* vs. Naive ^ vs. 3 dpi \# vs. 28 dpi

FIG. 1. Intraspinal histone deacetylase (HDAC) messenger RNA (mRNA) expression is altered after moderate spinal cord injury (SCI) in rats. A temporal gene expression profile using real-time polymerase chain reaction (PCR) was conducted for HDAC $1,2,3$, and 11 after spinal contusion injury at T8 in rats. HDAC1 was not altered after SCl; HDAC-2 and 3 were significantly down-regulated by 1 week postinjury and remained low at $14 \mathrm{dpi}(\mathbf{a}-\mathbf{c})$. HDAC-11 mRNA levels decreased at 3 dpi then returned to naïve levels by 14 dpi (d). ${ }^{*} p<0.05$ vs naïve; ${ }^{*} p<0.01$ vs naïve; ${ }^{\wedge} p p<0.01$ vs $3 \mathrm{dpi}$, , $\# p<0.05$ vs $28 \mathrm{dpi}$.

needed to clarify the environment in which these cells will be functioning.

\section{SAFEGUARDING OLIGODENDROCYTES}

Although spontaneous OL genesis and remyelination occur after SCI, it is clear that decreasing OL death would prevent early demyelination and may reduce axon degeneration and improve axon function. Thus, numerous therapeutic strategies have been tested to increase post-SCI OL survival. Several studies have shown that the anti-inflammatory agent minocycline promotes white matter sparing and OL protection after SCI, in part by inhibiting microglial production of pro-NGF [146-148]. Lee et al. [149] showed that methylprednisolone, a common treatment after SCI, protected OLs, but not neurons by blocking apoptosis. Methylprednisolonemediated effects on OL protection in SCI patients have not yet been explored. Whitaker et al. [150] showed rolipram, an inhibitor of the cAMP-dependent phosphodiesterase 4 (PDE4), protects OLs from secondary injury cascades at 24 to $72 \mathrm{~h}$ after injury. In a follow-up study, rolipram was reported to increase axon conduction due to remyelination, which was associated with improved behavioral outcomes [151].

Treatment with growth factors has also been attempted after SCI. For instance, administration of LIF, a cytokine implicated in OL survival, after SCI resulted in increased viability of OLs and decreased demyelination [152]. Exogenous BDNF treatment starting immediately or 3 days after injury decreased the number of apoptotic OLs [153]. Another group similarly demonstrated retrograde transport of BDNF via intramuscular injections in rats suppressed OL apoptosis after SCI [154]. Combining growth factor treatment and genetic manipulation of endogenous progenitors has also been attempted in rodent SCI [155]. The results showed that over-expression of MASH1/achaete-scute homolog 1 in conjunction with FGF-2 and EGF administration increased endogenous formation of OLs. Thus, several therapies targeting OL protection show promise in rodent SCI models.

\section{NEW OLS WITH TRANSPLANTATION}

Chronic persistence of demyelinated axons in the injured spinal cord of rodents [156] and humans [9] 


\begin{abstract}
OL PROTECTIVE
STRATEGIES

NORMAL SPINAL CORD
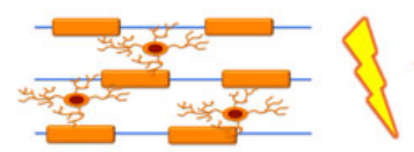

OPC

TRANSPLANTATION

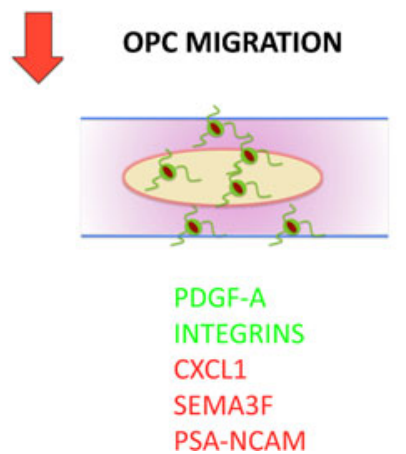

INJURED SPINAL CORD

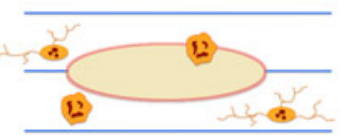

AXON

DEMYELINATION

OL NECROSIS

OL APOPTOSIS

\section{OL FORMATION}

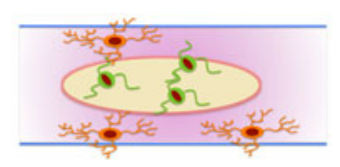

TH

PPAR- $\delta$

LIF

TGF- $\beta$

p27 kip1

OPC PROLIFERATION
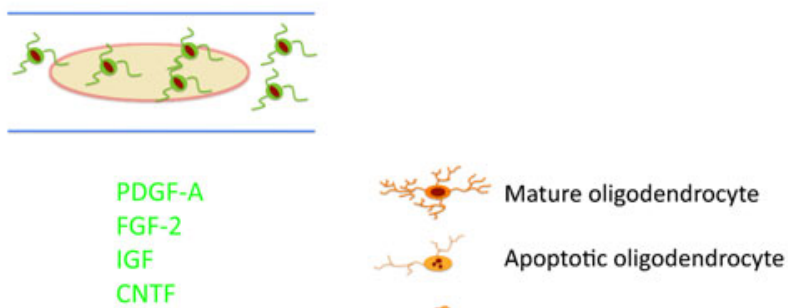

Necrotic oligodendrocyte

Oligodendrocyte progenitor cell

FIG. 2. Schematic of events involved in oligogenesis after injury to the spinal cord. This schematic represents that the normal spinal cord has axons myelinated by the oligodendrocytes (OL); however, after spinal cord injury (SCl), a series of events ensues that contribute to OL loss (see black) and formation. There is dramatic loss of OLs due to necrotic and apoptotic cell death resulting in axonal demyelination. Acute OL protective strategies (blue) after injury may help salvage OLs and prevent further loss. Oligodendrocyte progenitor cells (OPC) present in the spinal cord react to injury with extensive proliferation in the presence of numerous growth factors and cytokines. Once the OPCs proliferate, environmental and axonal cues regulate OPC migration to denuded axons. After reaching their destination, OPCs differentiate into mature OLs due to axonal signals and/or environmental factors, resulting in remyelination of the axons. Supplementing with stimulatory (green) and inhibitory (red) factors involved in each of the steps can further enhance endogenous OL formation. A common approach to increase OL numbers is subacute cell transplantation (blue), which is another therapeutic intervention that bolsters remyelination of axons after SCI. FGF-2 = fibroblast growth factor-2; IGF = insulin-like growth factor; PDGF-A = platelet-derived growth factor-A; CNTF = ciliary neurotrophic factor; LINGO = leucine rich repeat and Ig domain containing; PSA-NCAM = polysialylated form of the neural cell adhesion molecule; NOGO = neurite outgrowth inhibitor; SEMA3F = Semaphorin-3F.
\end{abstract}

serves as a potential therapeutic target. In addition to preservation of OLs and boosting endogenous oligogenesis, recent strategies have used transplantation of pluripotent/glial restricted cells to improve remyelination after SCI. Although a variety of transplant studies have been conducted with distinct sources and cell types in SCI models, we will highlight a few relevant studies here that focus on CNS stem-cell based transplants (for excellent reviews, see Enzmann et al. [157], Coutts et al. [158], and Kulbatski et al. [159]). Early work by Utzschneider et al. [48] served as proof of principal that transplantation of OLs in myelin-deficient animals would lead to remyelination and axon potential conduction velocity to near normal values. One of the first experiments to test transplantation from a therapeutic standpoint was conducted in an ethidium bromidedemyelinating lesion in which postnatally derived OPCs remyelinated spinal cord lesions [160]. Subsequent studies showed that OPC transplant-derived remyelina- tion resulted in reversal of functional deficits after demyelination [161]. Lee et al. [162] conducted a systematic analysis of transplantation of OPCs at 1 week postinjury in a rat spinal contusion model. They showed that OPCs migrated around the injury site and differentiated into mature OLs (not astrocytes or neurons). The transplants also improved functional recovery and increased the number of retrograde-labeled neurons in the brainstem.

An undifferentiated and pliable source of cell transplants is embryonic stem cells (ESC). McDonald et al. [163] tested the efficacy of transplanting neurally differentiated cells derived from mouse ESC into an injured rat spinal cord at $9 \mathrm{dpi}$. The cells survived, migrated, and differentiated into neurons, astrocytes, and OLs, resulting in significantly improved locomotor recovery [163]. In contrast, when undifferentiated rat neural stem cells were engrafted into injured cords, the majority of cells took on an astrocytic fate or remained as nestin positive cells 
[164]. This discrepancy was attributed to species-specific differences in cell sources (rat $v s$ mouse). The authors also suggested a prior need to differentiate the cells in vitro into restricted lineages before transplantation. The same group demonstrated that transplantation of embryonic glial restricted precursor cells over-expressing BDNF and NT-3 at 9 days after injury resulted in increased OL formation (15-30\%), enhanced remyelination, and restored electrophysiological conduction resulting in improved locomotor function [165].

The importance of human ESC as a potential therapeutic strategy has been underscored and has been tested in multiple studies. When transplanted, these cells survived, differentiated into OLs, remyelinated axons, and mediated locomotor improvements in injured Severe Combined Immunodeficiency (SCID) mice [166]. Keirstead et al. [167] differentiated human ESCs into a pure population of OPCs in vitro and transplanted the cells at 1 week or 10 months after SCI in rats. The grafted OPCs survived, integrated, migrated, and differentiated into OLs at both time points after injury. However, OLs formed by acute transplants enhanced remyelination and improved behavioral scores, whereas the chronic transplants failed to do so. Thus, the window of opportunity for stem cell transplantation clearly closes at some point.

As the use of ESCs raises a number of ethical issues, newer studies are geared toward using adult cells, especially because patients could undergo autologous transplants. The combinatorial action of transplanting adult neural precursor cells 2 weeks after SCI in conjunction with minocycline treatment and a cocktail of growth factors showed robust differentiation of transplant cells into myelinating OLs that remyelinated axons and improved recovery on a battery of behavioral measures [168]. When transplants were performed at a more chronic time ( 8 weeks), again beneficial effects were not observed [167]. Other promising anatomical and behavioral results were seen when adult neural precursor cells were transplanted at 2 weeks, but not 8 weeks, postinjury in combination with immunosuppression and minocycline; $\sim 50 \%$ of the cells differentiated into OL lineage cells and ensheathed spinal axons [168]. The reason for the limited window of opportunity for success in remyelinating cell transplants has been suggested to be the presence of astrocytic processes surrounding the demyelinated axons, which prevent the transplanted cells from reaching and remyelinating the axons [167]. Thus, performing transplants prior to the establishment of astrogliosis, or devising a way in which transplanted cells can intermingle between the astrocyte processes and axons, may be required for this strategy to work.

More recent data from the same group show exciting results when NPC transplants were combined with growth factor and chondroitinase treatment; the results revealed not only enhanced OL formation by transplant cells, but also increased growth of descending axons [169]. Another recent study transplanted OPCs engineered to over-express CNTF, which increased transplant survival, integration, and differentiation into OLs [170]. The grafted cells remyelinated spinal axons, improved electrophysiological conduction and enhanced hind limb recovery in rats. A potential negative effect of stem cell transplantation was demonstrated by Hofstetter et al. [171], who noted that although adult neural stem cell transplants improved motor function after SCI, recovery was accompanied by allodynia due to graft-mediated axonal sprouting. Thus, caution should be used in transplant studies, as is true with any therapeutic manipulation.

The multiple studies showing efficacy of stem cell transplants culminated in the United Stated Food and Drug Administration approval of phase I clinical trials by Geron Corporation in which OPCs derived from human embryonic stem cells will be transplanted acutely (within 14 days) in 8 to 10 patients with complete American Spinal Injury Association (ASIA) A injuries. The first patient was enrolled in October 2010. This clinical trial represents an exciting advancement in SCI treatment in general and highlights the importance of the need for continued research centered on promoting endogenous repair responses, as well as providing therapeutic options to reduce cell death and increase cell replacement after SCI. Only with ongoing basic and clinical research can the devastating effects of spinal trauma become a thing of the past.

Acknowledgments: The conflict of interest disclosure is available in the electronic supplementary material for this article.

\section{References}

1. Profyris C, Cheema SS, Zang D, Azari MF, Boyle K, Petratos S. Degenerative and regenerative mechanisms governing spinal cord injury. Neurobiol Dis 2004;15:415-436.

2. Grossman SD, Rosenberg LJ, Wrathall JR. Temporal-spatial pattern of acute neuronal and glial loss after spinal cord contusion. Exp Neurol 2001;168:273-282.

3. Crowe MJ, Bresnahan JC, Shuman SL, Masters JN, Beattie MS. Apoptosis and delayed degeneration after spinal cord injury in rats and monkeys. Nat Med 1997;3:73-76.

4. Casha S, Yu WR, Fehlings MG. Oligodendroglial apoptosis occurs along degenerating axons and is associated with FAS and p75 expression following spinal cord injury in the rat. Neuroscience 2001;103:203-218.

5. Liu XZ, Xu XM, Hu R, et al. Neuronal and glial apoptosis after traumatic spinal cord injury. J Neurosci 1997;17:5395-5406.

6. Li GL, Farooque M, Holtz A, Olsson Y. Apoptosis of oligodendrocytes occurs for long distances away from the primary injury after compression trauma to rat spinal cord. Acta Neuropathol 1999;98:473-480.

7. Lytle JM, Wrathall JR. Glial cell loss, proliferation and replacement in the contused murine spinal cord. Eur J Neurosci 2007;25:17111724.

8. Warden P, Bamber NI, Li H, et al. Delayed glial cell death following wallerian degeneration in white matter tracts after spinal 
cord dorsal column cordotomy in adult rats. Exp Neurol 2001;168:213-224.

9. Guest JD, Hiester ED, Bunge RP. Demyelination and Schwann cell responses adjacent to injury epicenter cavities following chronic human spinal cord injury. Exp Neurol 2005;192:384-393.

10. Emery E, Aldana P, Bunge MB, et al. Apoptosis after traumatic human spinal cord injury. J Neurosurg 1998;89:911-920.

11. Juliet PA, Frost EE, Balasubramaniam J, Del Bigio MR. Toxic effect of blood components on perinatal rat subventricular zone cells and oligodendrocyte precursor cell proliferation, differentiation and migration in culture. J Neurdochem 2009;109:1285-1299.

12. Thorburne SK, Juurlink BH. Low glutathione and high iron govern the susceptibility of oligodendroglial precursors to oxidative stress. J Neurochem 1996;67:1014-1022.

13. McAdoo DJ, Xu GY, Robak G, Hughes MG. Changes in amino acid concentrations over time and space around an impact injury and their diffusion through the rat spinal cord. Exp Neurol 1999;159:538-544.

14. Xu GY, Hughes MG, Ye Z, Hulsebosch CE, McAdoo DJ. Concentrations of glutamate released following spinal cord injury kill oligodendrocytes in the spinal cord. Exp Neurol 2004;187:329-336.

15. Karadottir R, Attwell D. Neurotransmitter receptors in the life and death of oligodendrocytes. Neuroscience 2007;145:1426-1438.

16. Gudz TI, Komuro H, Macklin WB. Glutamate stimulates oligodendrocyte progenitor migration mediated via an alphav integrin/ myelin proteolipid protein complex. J Neurosci 2006;26:24582466.

17. Wang X, Arcuino G, Takano T, et al. P2X7 receptor inhibition improves recovery after spinal cord injury. Nat Med 2004;10:821827.

18. Matute C, Torre I, Perez-Cerda F, et al. P2X(7) receptor blockade prevents ATP excitotoxicity in oligodendrocytes and ameliorates experimental autoimmune encephalomyelitis. J Neurosci 2007;27:9525-9533.

19. Domercq M, Perez-Samartin A, Aparicio D, Alberdi E, Pampliega $\mathrm{O}$, Matute C. P2X7 receptors mediate ischemic damage to oligodendrocytes. Glia 2010;58:730-740.

20. Butt AM. Neurotransmitter-mediated calcium signalling in oligodendrocyte physiology and pathology. Glia 2006;54:666675.

21. Pineau I, Lacroix S. Proinflammatory cytokine synthesis in the injured mouse spinal cord: multiphasic expression pattern and identification of the cell types involved. J Comp Neurol 2007;500:267-285.

22. Donnelly DJ, Popovich PG. Inflammation and its role in neuroprotection, axonal regeneration and functional recovery after spinal cord injury. Exp Neurol 2008;209:378-388.

23. Takahashi JL, Giuliani F, Power C, Imai Y, Yong VW. Interleukin1 beta promotes oligodendrocyte death through glutamate excitotoxicity. Ann Neurol 2003;53:588-595.

24. Popovich PG, Wei P, Stokes BT. Cellular inflammatory response after spinal cord injury in Sprague- Dawley and Lewis rats. J Comp Neurol 1997;377:43-464.

25. Antel JP, Williams K, Blain M, McRea E, McLaurin J. Oligodendrocyte lysis by CD4+ T cells independent of tumor necrosis factor. Ann Neurol 1994;35:341-348.

26. D'Souza SD, Bonetti B, Balasingam V, et al. Multiple sclerosis: Fas signaling in oligodendrocyte cell death. J Exp Med 1996;184:2361-2370.

27. Demjen D, Klussmann S, Kleber S, et al. Neutralization of CD95 ligand promotes regeneration and functional recovery after spinal cord injury. Nat Med 2004;10:389-395.

28. Casaccia-Bonnefil P, Carter BD, Dobrowsky RT, Chao MV. Death of oligodendrocytes mediated by the interaction of nerve growth factor with its receptor p75. Nature 1996;383:716-719.

29. Kanno H, Ozawa H, Sekiguchi A, Itoi E. Spinal cord injury induces upregulation of Beclin 1 and promotes autophagic cell death. Neurobiol Dis 2009;33:143-148.

30. Sun F, Lin CL, McTigue D, et al. Effects of axon degeneration on oligodendrocyte lineage cells: dorsal rhizotomy evokes a repair response while axon degeneration rostral to spinal contusion induces both repair and apoptosis. Glia 2010;58:1304-1319.
31. Jones TB, McDaniel EE, Popovich PG. Inflammatory-mediated injury and repair in the traumatically injured spinal cord. Curr Pharm Des 2005;11:1223-1236.

32. Kotter MR, Setzu A, Sim FJ, Van Rooijen N, Franklin RJ. Macrophage depletion impairs oligodendrocyte remyelination following lysolecithin-induced demyelination. Glia 2001;35:204-212.

33. Wu J, Yoo S, Wilcock $\mathrm{D}$, et al. Interaction of $\mathrm{NG} 2(+)$ glial progenitors and microglia/macrophages from the injured spinal cord. Glia 2010;58:410-422.

34. Schonberg DL, Popovich PG, McTigue DM. Oligodendrocyte generation is differentially influenced by toll-like receptor (TLR) 2 and TLR4-mediated intraspinal macrophage activation. J Neuropathol Exp Neurol 2007;66:1124-1135.

35. Schonberg DL, McTigue DM. Iron is essential for oligodendrocyte genesis following intraspinal macrophage activation. Exp Neurol 2009;218:64-74.

36. Zhang X, Surguladze N, Slagle-Webb B, Cozzi A, Connor JR. Cellular iron status influences the functional relationship between microglia and oligodendrocytes. Glia 2006;54:795-804.

37. Balentine JD. Pathology of experimental spinal cord trauma. II. Ultrastructure of axons and myelin. Lab Invest 1978;39:254266.

38. Banik NL, Powers JM, Hogan EL. The effects of spinal cord trauma on myelin. J Neuropathol Exp Neurol 1980;39:232-244.

39. Horrocks LA, Toews A, Yashon D, Locke GE. Changes in myelin following trauma of the spinal cord in monkeys. Neurobiology 1973;3:256-263.

40. Gledhill RF, Harrison BM, McDonald WI. Demyelination and remyelination after acute spinal cord compression. Exp Neurol 197338:472-487.

41. Harrison BM, McDonald WI. Remyelination after transient experimental compression of the spinal cord. Ann Neurol 1977;1:542-551.

42. Blight AR. Delayed demyelination and macrophage invasion: a candidate for secondary cell damage in spinal cord injury. Cent Nerv Syst Trauma 1985;2:299-315.

43. Smith PM, Jeffery ND. Histological and ultrastructural analysis of white matter damage after naturally-occurring spinal cord injury. Brain Pathol 2006;16:99-109.

44. Bunge MB, Bunge RP, Ris H. Ultrastructural study of remyelination in an experimental lesion in adult cat spinal cord. J Biophys Biochem Cytol 1961;10:67-94.

45. Bunge RP, Bunge MB, Rish. Electron microscopic study of demyelination in an experimentally induced lesion in adult cat spinal cord. J Biophys Biochem Cytol 1960;7:685-696.

46. Griffiths IR, McCulloch MC. Nerve fibres in spinal cord impact injuries. Part 1. Changes in the myelin sheath during the initial 5 weeks. J Neurol Sci 1983;58:335-349.

47. Smith EJ, Blakemore WF, McDonald WI. Central remyelination restores secure conduction. Nature 1979;280:395-396.

48. Utzschneider DA, Archer DR, Kocsis JD, Waxman SG, Duncan ID. Transplantation of glial cells enhances action potential conduction of amyelinated spinal cord axons in the myelin-deficient rat. Proc Natl Acad Sci U S A 1994;91:53-57.

49. Jeffery ND, Blakemore WF. Locomotor deficits induced by experimental spinal cord demyelination are abolished by spontaneous remyelination. Brain 1997;120(Pt 1):27-37.

50. Dutta R, Trapp BD. Pathogenesis of axonal and neuronal damage in multiple sclerosis. Neurology 2007;68(22 suppl 3): S22-S31.

51. Kassmann CM, Lappe-Siefke C, Baes M, et al. Axonal loss and neuroinflammation caused by peroxisome-deficient oligodendrocytes. Nat Genet 2007;39:969-976.

52. Grigoriadis N, Ben-Hur T, Karussis D, Milonas I. Axonal damage in multiple sclerosis: a complex issue in a complex disease. Clin Neurol Neurosurg 2004;106:211-217.

53. Blakemore WF, Keirstead HS. The origin of remyelinating cells in the central nervous system. J Neuroimmunol 1999;98:69-76.

54. Wolswijk G, Noble M. Identification of an adult-specific glial progenitor cell. Development 1989;105:387-400.

55. Watanabe M, Toyama Y, Nishiyama A. Differentiation of proliferated NG2-positive glial progenitor cells in a remyelinating lesion. J Neurosci Res 2002;69:826-836. 
56. Carroll WM, Jennings AR, Ironside LJ. Identification of the adult resting progenitor cell by autoradiographic tracking of oligodendrocyte precursors in experimental CNS demyelination. Brain 1998;121(Pt 2):293-302.

57. Nishiyama A, Komitova M, Suzuki R, Zhu X. Polydendrocytes (NG2 cells): multifunctional cells with lineage plasticity. Nat Rev Neurosci 2009;10:9-22.

58. Trotter J, Karram K, Nishiyama A. NG2 cells: Properties, progeny and origin. Brain Res Rev 2010;63:72-82.

59. McTigue DM, Wei P, Stokes BT. Proliferation of NG2-positive cells and altered oligodendrocyte numbers in the contused rat spinal cord. J Neurosci 2001;21:3392-3400.

60. Zai LJ, Wrathall JR. Cell proliferation and replacement following contusive spinal cord injury. Glia 2005;50:247-257.

61. Rabchevsky AG, Sullivan PG, Scheff SW. Temporal-spatial dynamics in oligodendrocyte and glial progenitor cell numbers throughout ventrolateral white matter following contusion spinal cord injury. Glia 2007;55:831-843.

62. Lytle JM, Vicini S, Wrathall JR. Phenotypic changes in NG2+ cells after spinal cord injury. J Neurotrauma 2006;23:17261738 .

63. Horky LL, Galimi F, Gage FH, Horner PJ. Fate of endogenous stem/progenitor cells following spinal cord injury. J Comp Neurol 2006;498:525-538.

64. Yang H, Lu P, McKay HM, et al. Endogenous neurogenesis replaces oligodendrocytes and astrocytes after primate spinal cord injury. J Neurosci 2006;26:2157-2166.

65. Yoo S, Wrathall JR. Mixed primary culture and clonal analysis provide evidence that NG2 proteoglycan-expressing cells after spinal cord injury are glial progenitors. Dev Neurobiol 2007;67:860-874.

66. Tripathi R, McTigue DM. Prominent oligodendrocyte genesis along the border of spinal contusion lesions. Glia 2007;55:698-711.

67. Tripathi RB, McTigue DM. Chronically increased ciliary neurotrophic factor and fibroblast growth factor-2 expression after spinal contusion in rats. J Comp Neurol 2008;510:129-144.

68. Sellers DL, Maris DO, Horner PJ. Postinjury niches induce temporal shifts in progenitor fates to direct lesion repair after spinal cord injury. J Neurosci 2009;29:6722-6733.

69. Barnabe-Heider F, Goritz C, Sabelstrom H, et al. Origin of new glial cells in intact and injured adult spinal cord. Cell Stem Cell 2010;7:470-482.

70. Lytle JM, Chittajallu R, Wrathall JR, Gallo V. NG2 cell response in the CNP-EGFP mouse after contusive spinal cord injury. Glia 2009;57:270-285.

71. Nicolay DJ, Doucette JR, Nazarali AJ. Transcriptional control of oligodendrogenesis. Glia 2007;55:1287-1299.

72. Chen J, Leong SY, Schachner M. Differential expression of cell fate determinants in neurons and glial cells of adult mouse spinal cord after compression injury. Eur J Neurosci 2005;22:1895-1906.

73. Hampton DW, Asher RA, Kondo T, Steeves JD, Ramer MS, Fawcett JW. A potential role for bone morphogenetic protein signalling in glial cell fate determination following adult central nervous system injury in vivo. Eur J Neurosci 2007;26:3024-3035.

74. Sahni V, Mukhopadhyay A, Tysseling V, et al. BMPR1a and BMPR1b signaling exert opposing effects on gliosis after spinal cord injury. J Neurosci 2010;30:1839-1855.

75. Mabie PC, Mehler MF, Marmur R, Papavasiliou A, Song Q, Kessler JA. Bone morphogenetic proteins induce astroglial differentiation of oligodendroglial-astroglial progenitor cells. J Neurosci 1997; 17:4112-4120.

76. Lu HZ, Wang YX, Zou J, et al. Differentiation of neural precursor cell-derived oligodendrocyte progenitor cells following transplantation into normal and injured spinal cords. Differentiation 2010;80:228-240.

77. Raff MC, Lillien LE, Richardson WD, Burne JF, Noble MD. Platelet-derived growth factor from astrocytes drives the clock that times oligodendrocyte development in culture. Nature 1988;333:562-565.

78. Noble M, Murray K, Stroobant P, Waterfield MD, Riddle P. Platelet-derived growth factor promotes division and motility and inhibits premature differentiation of the oligodendrocyte/type-2 astrocyte progenitor cell. Nature 1988;333:560-562.
79. Fruttiger M, Karlsson L, Hall AC, et al. Defective oligodendrocyte development and severe hypomyelination in PDGF-A knockout mice. Development 1999;126:457-467.

80. Calver AR, Hall AC, Yu WP, et al. Oligodendrocyte population dynamics and the role of PDGF in vivo. Neuron 1998;20:869-882.

81. Richardson WD, Pringle N, Mosley MJ, Westermark B, DuboisDalcq M. A role for platelet-derived growth factor in normal gliogenesis in the central nervous system. Cell 1998;53:309-319.

82. Velardo MJ, Burger C, Williams PR, et al. Patterns of gene expression reveal a temporally orchestrated wound healing response in the injured spinal cord. J Neurosci 2004;24:8562-8576.

83. Mason JL, Goldman JE. A2B5+ and O4+ Cycling progenitors in the adult forebrain white matter respond differentially to PDGFAA, FGF-2, and IGF-1. Mol Cell Neurosci 2002;20:30-42.

84. Wolswijk G, Noble M. Cooperation between PDGF and FGF converts slowly dividing O-2Aadult progenitor cells to rapidly dividing cells with characteristics of O-2Aperinatal progenitor cells. J Cell Biol 1992;118:889-900.

85. McKinnon RD, Matsui T, Dubois-Dalcq M, Aaronson SA. FGF modulates the PDGF-driven pathway of oligodendrocyte development. Neuron 1990;5:603-614.

86. Engel U, Wolswijk G. Oligodendrocyte-type-2 astrocyte (O-2A) progenitor cells derived from adult rat spinal cord: in vitro characteristics and response to PDGF, bFGF and NT-3. Glia 1996:16:16-26.

87. Mocchetti I, Rabin SJ, Colangelo AM, Whittemore SR, Wrathall JR. Increased basic fibroblast growth factor expression following contusive spinal cord injury. Exp Neurol 1996;141:154-164.

88. Koshinaga M, Sanon HR, Whittemore SR. Altered acidic and basic fibroblast growth factor expression following spinal cord injury. Exp Neurol 1993;120:32-48.

89. Zai LJ, Yoo S, Wrathall JR. Increased growth factor expression and cell proliferation after contusive spinal cord injury. Brain Res 2005; 1052:147-155

90. Cunha JD, Levy BDA, de Luca BA, de Andrade MSR, Gomide VC, Chadi G. Responses of reactive astrocytes containing S100 beta protein and fibroblast growth factor- 2 in the border and in the adjacent preserved tissue after a contusion injury of the spinal cord in rats: implications for wound repair and neuroregeneration. Wound Repair Regen 2007;15:134-146.

91. Barres BA, Hart IK, Coles HS, et al. Cell death and control of cell survival in the oligodendrocyte lineage. Cell 1992;70:31-46.

92. McMorris FA, Dubois-Dalcq M. Insulin-like growth factor I promotes cell proliferation and oligodendroglial commitment in rat glial progenitor cells developing in vitro. J Neurosci Res 1998;21:199-209.

93. Yao DL, West NR, Bondy CA, et al. Cryogenic spinal cord injury induces astrocytic gene expression of insulin-like growth factor 1 and insulin-like growth factor binding protein 2 during myelin regeneration. J Neurosci Res 1995;40:647-659.

94. Jiang F, Frederick TJ, Wood TL. IGF-I synergizes with FGF-2 to stimulate oligodendrocyte progenitor entry into the cell cycle. Dev Biol 2001;232:414-423.

95. Louis JC, Magal E, Takayama S, Varon S. CNTF protection of oligodendrocytes against natural and tumor necrosis factorinduced death. Science 1993;259:689-692.

96. Barres BA, Schmid R, Sendnter M, Raff MC. Multiple extracellular signals are required for long-term oligodendrocyte survival. Development 1993;118:283-295.

97. Oyesiku NM, Wilcox JN, Wigston DJ. Changes in expression of ciliary neurotrophic factor (CNTF) and CNTF-receptor alpha after spinal cord injury. J Neurobiol 1997;32:251-261.

98. Albrecht PJ, Dahl JP, Stoltzfus OK, Levenson R, Levison SW. Ciliary neurotrophic factor activates spinal cord astrocytes, stimulating their production and release of fibroblast growth factor-2, to increase motor neuron survival. Exp Neurol 2002;173:46-62.

99. Jiang F, Levison SW, Wood TL. Ciliary neurotrophic factor induces expression of the IGF type I receptor and FGF receptor 1 mRNAs in adult rat brain oligodendrocytes. J Neurosci Res 1999;57:447-457.

100. Barres BA, Raff MC, Gaese F, Bartke I, Dechant G, Barde YA. A crucial role for neurotrophin-3 in oligodendrocyte development. Nature 1994;367:371-375. 
101. Cohen RI, Marmur R, Norton WT, Mehler MF, Kessler JA. Nerve growth factor and neurotrophin-3 differentially regulate the proliferation and survival of developing rat brain oligodendrocytes. J Neurosci 1996;16:6433-6442.

102. Li XL, Zhang W, Zhou X, et al. Temporal changes in the expression of some neurotrophins in spinal cord transected adult rats. Neuropeptides 2007;41:135-143.

103. Zhang HT, Gao ZY, Chen YZ, Wang TH. Temporal changes in the level of neurotrophins in the spinal cord and associated precentral gyrus following spinal hemisection in adult Rhesus monkeys. J Chem Neuroanat 2008;36:138-143.

104. Qin DX, Zou XL, Luo W, et al. Expression of some neurotrophins in the spinal motoneurons after cord hemisection in adult rats. Neurosci Lett 2006;410:222-227.

105. McTigue DM, Horner PJ, Stokes BT, Gage FH. Neurotrophin3 and brain-derived neurotrophic factor induce oligodendrocyte proliferation and myelination of regenerating axons in the contused adult rat spinal cord. J Neurosci 1998;18:53545365 .

106. McTigue DM, Tani M, Krivacic K, et al. Selective chemokine mRNA accumulation in the rat spinal cord after contusion injury. $\mathrm{J}$ Neurosci Res 1998;53:368-376.

107. Patel JR, McCandless EE, Dorsey D, Klein RS. CXCR4 promotes differentiation of oligodendrocyte progenitors and remyelination. Proc Natl Acad Sci U S A 2010;107:11062-11067.

108. Dziembowska M, Tham TN, Lau P, Vitry S, Lazarini F, DuboisDalcq M. A role for CXCR4 signaling in survival and migration of neural and oligodendrocyte precursors. Glia 2005;50:258-269.

109. Robinson S, Tani M, Strieter RM, Ransohoff RM, Miller RH. The chemokine growth-regulated oncogene-alpha promotes spinal cord oligodendrocyte precursor proliferation. J Neurosci 1998;18:10457-10463.

110. Knerlich-Lukoschus F, von der Ropp-Brenner B, Lucius R, Mehdorn HM, Held-Feindt J. Chemokine expression in the white matter spinal cord precursor niche after force-defined spinal cord contusion injuries in adult rats. Glia 2010;58:916-931.

111. Vela JM, Molina-Holgado E, Arevalo-Martin A, Almazan G, Guaza C. Interleukin-1 regulates proliferation and differentiation of oligodendrocyte progenitor cells. Mol Cell Neurosci 2002;20:489-502.

112. Mayer M, Bhakoo K, Noble M. Ciliary neurotrophic factor and leukemia inhibitory factor promote the generation, maturation and survival of oligodendrocytes in vitro. Development 1994;120:143-153.

113. Pan W, Cain C, Yu Y, Kastin AJ. Receptor-mediated transport of LIF across blood-spinal cord barrier is upregulated after spinal cord injury. J Neuroimmunol 2006;174:119-125.

114. Semple-Rowland SL, Mahatme A, Popovich PG, et al. Analysis of TGF-beta 1 gene expression in contused rat spinal cord using quantitative RT-PCR. J Neurotrauma 1995;12:1003-1014.

115. McTigue DM, Popovich PG, Morgan TE, Stokes BT. Localization of transforming growth factor-betal and receptor mRNA after experimental spinal cord injury. Exp Neurol 2000;163:220-230.

116. Buss A, Pech K, Kakulas BA, et al. TGF-beta1 and TGF-beta2 expression after traumatic human spinal cord injury. Spinal Cord 2008;46:364-371.

117. Yu C, Takeda M, Soliven B. Regulation of cell cycle proteins by TNF-alpha and TGF-beta in cells of oligodendroglial lineage. J Neuroimmunol 2000;108:2-10.

118. McKinnon RD, Piras G, Ida JA Jr., Dubois-Dalcq M. A role for TGF-beta in oligodendrocyte differentiation. J Cell Biol 1993;121:1397-1407.

119. Zhang Y, Zhang J, Navrazhina K, et al. TGFbetal induces Jagged1 expression in astrocytes via ALK5 and Smad3 and regulates the balance between oligodendrocyte progenitor proliferation and differentiation. Glia 2010;58:964-974.

120. Cheville AL, Kirshblum SC. Thyroid hormone changes in chronic spinal cord injury. J Spinal Cord Med 1995;18:227-232.

121. Baas D, Legrand C, Samarut J, Flamant F. Persistence of oligodendrocyte precursor cells and altered myelination in optic nerve associated to retina degeneration in mice devoid of all thyroid hormone receptors. Proc Natl Acad Sci U S A 2002;99:2907-2911.
122. Granneman J, Skoff R, Yang X. Member of the peroxisome proliferator-activated receptor family of transcription factors is differentially expressed by oligodendrocytes. J Neurosci Res 1998;51:563-573.

123. Saluja I, Granneman JG, Skoff RP. PPAR delta agonists stimulate oligodendrocyte differentiation in tissue culture. Glia 2001;33:191-204.

124. Noll E, Miller RH. Regulation of oligodendrocyte differentiation: a role for retinoic acid in the spinal cord. Development 1994;120:649-660.

125. Almad A, McTigue DM. Chronic expression of PPAR-delta by oligodendrocyte lineage cells in the injured rat spinal cord. J Comp Neurol 2010;518:785-799.

126. Kern J, Schrage K, Koopmans GC, Joosten EA, McCaffery P, Mey J. Characterization of retinaldehyde dehydrogenase-2 induction in NG2-positive glia after spinal cord contusion injury. Int.J. Dev.Neurosci 2007;25:7-16.

127. Wang S, Sdrulla AD, di Sibio G, et al. Notch receptor activation inhibits oligodendrocyte differentiation. Neuron 1998;21:63-75.

128. Yamamoto S, Nagao M, Sugimori M, et al. Transcription factor expression and Notch-dependent regulation of neural progenitors in the adult rat spinal cord. J Neurosci 2001;21:9814-9823.

129. Fewou SN, Ramakrishnan H, Bussow H, Gieselmann V, Eckhardt M. Down-regulation of polysialic acid is required for efficient myelin formation. J Biol Chem 2007;282:16700-16711.

130. Charles P, Reynolds R, Seilhean D, et al. Re-expression of PSANCAM by demyelinated axons: an inhibitor of remyelination in multiple sclerosis? Brain 2002;125(Pt 9):1972-1979.

131. Charles P, Hernandez MP, Stankoff B, et al. Negative regulation of central nervous system myelination by polysialylated-neural cell adhesion molecule. Proc Natl Acad Sci U S A 2000;97:75857590.

132. Camand E, Morel MP, Faissner A, Sotelo C, Dusart I. Long-term changes in the molecular composition of the glial scar and progressive increase of serotoninergic fibre sprouting after hemisection of the mouse spinal cord. Eur J Neurosci 2004;20:11611176.

133. Mi S, Lee X, Shao Z, et al. LINGO-1 is a component of the Nogo66 receptor/p75 signaling complex. Nat Neurosci 2004;7:221228.

134. Mi S, Miller RH, Lee X, et al. LINGO-1 negatively regulates myelination by oligodendrocytes. Nat Neurosci $2005 ; 8: 745$ 751.

135. Ji B, Li M, Wu WT, et al. LINGO-1 antagonist promotes functional recovery and axonal sprouting after spinal cord injury. Mol.Cell Neurosci 2006;33:311-320.

136. Liu H, Hu Q, D'Ercole A J, Ye P. Histone deacetylase 11 regulates oligodendrocyte-specific gene expression and cell development in OL-1 oligodendroglia cells. Glia 2009;57:1-12.

137. Marin-Husstege M, Muggironi M, Liu A, Casaccia-Bonnefil P. Histone deacetylase activity is necessary for oligodendrocyte lineage progression. J Neurosci 2002;22:10333-10345.

138. Shen S, Sandoval J, Swiss VA et al. Age-dependent epigenetic control of differentiation inhibitors is critical for remyelination efficiency. Nat Neurosci 2008;11:1024-1034.

139. Dincman TA BJ, Ohri SS, Kuypers NJ, Gallo V, Whittemore SR. Histone Deacetylase responses to contusive spinal cord injury and ER Stress in mouse oligodendrocyte precursor cells In: Neuroscience Meeting Planner, San Diego, CA: Society for Neuroscience, 2010.

140. Lau P, Verrier JD, Nielsen JA, Johnson KR, Notterpek L, Hudson LD. Identification of dynamically regulated microRNA and mRNA networks in developing oligodendrocytes. J Neurosci 2008;28:11720-11730.

141. Dugas JC, Cuellar TL, Scholze A, et al. Dicer1 and miR-219 Are required for normal oligodendrocyte differentiation and myelination. Neuron 2010;65:597-611.

142. Zhao X, He X, Han X, et al. MicroRNA-mediated control of oligodendrocyte differentiation. Neuron 2010;65:612-626.

143. Zheng K, Li H, Zhu Y, Zhu Q, Qiu M. MicroRNAs are essential for the developmental switch from neurogenesis to gliogenesis in the developing spinal cord. J Neurosci 2010;30:8245-8250. 
144. Liu NK, Wang XF, Lu QB, Xu XM. Altered microRNA expression following traumatic spinal cord injury. Exp Neurol 2009;219:424-429.

145. Budde H, Schmitt S, Fitzner D, Opitz L, Salinas-Riester G, Simons M. Control of oligodendroglial cell number by the miR17-92 cluster. Development 2010;137:2127-2132.

146. Yune TY, Lee JY, Jung GY, et al. Minocycline alleviates death of oligodendrocytes by inhibiting pro-nerve growth factor production in microglia after spinal cord injury. J Neurosci 2007;27:7751-7761.

147. Teng YD, Choi H, Onario RC, et al. Minocycline inhibits contusion-triggered mitochondrial cytochrome $\mathrm{c}$ release and mitigates functional deficits after spinal cord injury. Proc Natl Acad Sci U S A 2004;101:3071-3076.

148. Stirling DP, Khodarahmi K, Liu J, et al. Minocycline treatment reduces delayed oligodendrocyte death, attenuates axonal dieback, and improves functional outcome after spinal cord injury. J Neurosci 2004;24:2182-2190.

149. Lee JM, Yan P, Xiao Q, et al. Methylprednisolone protects oligodendrocytes but not neurons after spinal cord injury. J Neurosci 2008;28:3141-3149.

150. Whitaker CM, Beaumont E, Wells MJ, Magnuson DS, Hetman M, Onifer SM. Rolipram attenuates acute oligodendrocyte death in the adult rat ventrolateral funiculus following contusive cervical spinal cord injury. Neurosci Lett 2008;438:200-204.

151. Beaumont E, Whitaker CM, Burke DA, Hetman M, Onifer SM Effects of rolipram on adult rat oligodendrocytes and functional recovery after contusive cervical spinal cord injury. Neuroscience 2009;163:985-990.

152. Azari MF, Profyris C, Karnezis T, et al. Leukemia inhibitory factor arrests oligodendrocyte death and demyelination in spinal cord injury. J Neuropathol Exp Neurol 2006;65:914-929.

153. Koda M, Murakami M, Ino H, et al. Brain-derived neurotrophic factor suppresses delayed apoptosis of oligodendrocytes after spinal cord injury in rats. J Neurotrauma 2002;19:777-785.

154. Nakajima H, Uchida K, Yayama T, et al. Targeted retrograde gene delivery of brain-derived neurotrophic factor suppresses apoptosis of neurons and oligodendroglia after spinal cord injury in rats. Spine 2010;35:497-504.

155. Ohori Y, Yamamoto S, Nagao M, et al. Growth factor treatment and genetic manipulation stimulate neurogenesis and oligodendrogenesis by endogenous neural progenitors in the injured adult spinal cord. J Neurosci 2006;26:11948-11960.

156. Totoiu MO, Keirstead HS. Spinal cord injury is accompanied by chronic progressive demyelination. J.Comp Neurol 2005; 486:373-383.

157. Enzmann GU, Benton RL, Talbott JF, Cao Q, Whittemore SR. Functional considerations of stem cell transplantation therapy for spinal cord repair. J Neurotrauma 2006;23:479-495.
158. Coutts M, Keirstead HS. Stem cells for the treatment of spinal cord injury. Exp Neurol 2008;209:368-377.

159. Kulbatski I, Mothe AJ, Parr AM, et al. Glial precursor cell transplantation therapy for neurotrauma and multiple sclerosis. Prog Histochem Cytochem 2008;43:123-176.

160. Groves AK, Barnett SC, Franklin RJ, et al. Repair of demyelinated lesions by transplantation of purified O-2A progenitor cells. Nature 1993;362:453-455.

161. Jeffery ND, Crang AJ, O'Leary M T, Hodge SJ, Blakemore WF Behavioural consequences of oligodendrocyte progenitor cell transplantation into experimental demyelinating lesions in the rat spinal cord. Eur J Neurosci 1999;11:1508-1514.

162. Lee KH, Yoon DH, Park YG, Lee BH. Effects of glial transplantation on functional recovery following acute spinal cord injury. J Neurotrauma 2005;22:575-589.

163. McDonald JW, Liu XZ, Qu Y, et al. Transplanted embryonic stem cells survive, differentiate and promote recovery in injured rat spinal cord. Nat Med 1999;5:1410-1412.

164. Cao QL, Zhang YP, Howard RM, Walters WM, Tsoulfas P, Whittemore SR. Pluripotent stem cells engrafted into the normal or lesioned adult rat spinal cord are restricted to a glial lineage. Exp Neurol 2001;167:48-58.

165. Cao Q, Xu XM, Devries WH, et al. Functional recovery in traumatic spinal cord injury after transplantation of multineurotrophin-expressing glial-restricted precursor cells. J Neurosci 2005;25:6947-6957

166. Cummings BJ, Uchida N, Tamaki SJ, et al. Human neural stem cells differentiate and promote locomotor recovery in spinal cord-injured mice. Proc Natl Acad Sci U S A 2005;102:14069-14074.

167. Keirstead HS, Nistor G, Bernal G, et al. Human embryonic stem cell-derived oligodendrocyte progenitor cell transplants remyelinate and restore locomotion after spinal cord injury. J Neurosci 2005;25:4694-4705.

168. Karimi-Abdolrezaee S, Eftekharpour E, Wang J, Morshead CM, Fehlings MG. Delayed transplantation of adult neural precursor cells promotes remyelination and functional neurological recovery after spinal cord injury. J Neurosci 2006;26:3377-3389.

169. Karimi-Abdolrezaee S, Eftekharpour E, Wang J, Schut D, Fehlings MG. Synergistic effects of transplanted adult neural stem/progenitor cells, chondroitinase, and growth factors promote functional repair and plasticity of the chronically injured spinal cord. J Neurosci 2010;30:1657-1676.

170. Cao Q, He Q, Wang Y, et al. Transplantation of ciliary neurotrophic factor-expressing adult oligodendrocyte precursor cells promotes remyelination and functional recovery after spinal cord injury. J Neurosci 2010;30:2989-3001.

171. Hofstetter CP, Holmstrom NA, Lilja JA, et al. Allodynia limits the usefulness of intraspinal neural stem cell grafts; directed differentiation improves outcome. Nat Neurosci 2005;8:346-353. 